\title{
Antimicrobial prophylaxis in adults and children undergoing hematopoietic cell transplantation: 2021 Polish recommendations
}

Jan Styczyński ${ }^{1 \# *}$ (D), Agnieszka Piekarska ${ }^{2 \#}$, Agnieszka Zaucha-Prażmo ${ }^{3}$, Jan Maciej Zaucha ${ }^{2}$,

Olga Zając-Spychała ${ }^{4}$, Tomasz Wróbel ${ }^{5}$, Agnieszka Wierzbowska ${ }^{6}$, Adam Walter-Croneck ${ }^{7}$, Jacek Wachowiak ${ }^{4}$, Marek Ussowicz ${ }^{8}$, Tomasz Szczepański ${ }^{9}$, Agnieszka Sobkowiak-Sobierajska ${ }^{4}$, Małgorzata Sobczyk-Kruszelnicka ${ }^{10}$, Katarzyna Smalisz ${ }^{11}$, Mariola Sędzimirska ${ }^{12}$, Piotr Rzepecki ${ }^{13}$, Beata Piątkowska-Jakubas ${ }^{14}$, Anna Łojko ${ }^{15}$, Ewa Lutwin ${ }^{16}$, Ewa Lech-Marańda ${ }^{17}$,

Bogusław Machaliński ${ }^{18}$, Aleksandra Krasowska-Kwiecień ${ }^{19}$, Krzysztof Kałwak ${ }^{8}$, Marek Hus ${ }^{7}$, Iwona Hus ${ }^{17}$, Grzegorz Helbig ${ }^{20}$, Dorota Hawrylecka ${ }^{21}$, Kazimierz Hałaburda ${ }^{17}$, Jolanta Goździk ${ }^{19}$,

Sebastian Giebel $^{10}$, Adam Fronczak ${ }^{6}$, Jarosław Dybko ${ }^{12}$, Agnieszka Druzd-Sitek ${ }^{22}$, Katarzyna Drabko ${ }^{3}$, Krzysztof Czyżewski ${ }^{1}$, Anna Czyż ${ }^{5}$, Edyta Cichocka ${ }^{23}$, Piotr Boguradzki ${ }^{24}$, Maria Bieniaszewska ${ }^{2}$, Bartłomiej Baumert ${ }^{18}$, Grzegorz Basak ${ }^{24}$, Lidia Gil ${ }^{15 \# \#}$

${ }^{1}$ Department of Pediatric Hematology and Oncology, Collegium Medicum in Bydgoszcz, Nicolaus Copernicus University in Toruń, Jurasz University Hospital 1, Bydgoszcz, Poland

${ }^{2}$ Department of Hematology and Transplantology, Medical University of Gdańsk, Gdańsk, Poland

${ }^{3}$ Department of Pediatric Hematology, Oncology and Transplantology, Medical University, Lublin, Poland

${ }^{4}$ Department of Pediatric Hematology, Oncology and Transplantology, Poznań University of Medical Sciences, Poznań, Poland

${ }^{5}$ Department of Hematology, Blood Neoplasms and Bone Marrow Transplantation, Medical University, Wrocław, Poland

${ }^{6}$ Department of Hematology, Medical University, Łódź, Poland

${ }^{7}$ Department of Hemato-oncology and Bone Marrow Transplantation, Medical University, Lublin, Poland

${ }^{8}$ Department of Pediatric Bone Marrow Transplantation, Oncology and Hematology, Wrocław Medical University, Wrocław, Poland

${ }^{9}$ Department of Pediatric Hematology and Oncology, Medical University of Silesia, Zabrze, Poland

${ }^{10}$ Department of Bone Marrow Transplantation and Oncohematology, Maria Skłodowska-Curie National Research Institute of Oncology Gliwice Branch, Gliwice, Poland

${ }^{11}$ Department of Pediatric Hematology and Oncology and Clinical Transplantology, Medical University, Warsaw, Poland

${ }^{12}$ Department of Hematology and Transplantology, Lower Silesian Oncology Center, Wrocław, Poland

${ }^{13}$ Department of Hematology, Military Institute of Medicine, Warsaw, Poland

${ }^{14}$ Department of Hematology, Medical College, Jagiellonian University, Kraków, Poland

${ }^{15}$ Department of Hematology and Bone Marrow Transplantation, Poznań University of Medical Sciences, Poznań, Poland

${ }^{16}$ Department of Hematology and Transplantology, Center of Oncology, Kielce, Poland

${ }^{17}$ Department of Hematology, Institute of Hematology and Transfusion Medicine, Warsaw, Poland

${ }^{18}$ Department of Hematology and Transplantology, Pomeranian Medical University, Szczecin, Poland

${ }^{19}$ Department of Transplantation, Children's University Hospital, Department of Clinical Immunology and Transplantology, Jagiellonian University Medical College, Kraków, Poland

*Address for correspondence: Jan Styczyński, Department of Pediatric Hematology and Oncology, Collegium Medicum, Nicolaus Copernicus University Toruń, ul. Skłodowskiej-Curie 9, 85-094 Bydgoszcz, Poland, phone +485258548 60, fax +485258540 87, e-mail: jstyczynski@cm.umk.pl Received: 05.09.2021

Accepted: 16.09 .2021

\section{PTH iT Copyright $\odot 2021$}

The Polish Society of Haematologists and Transfusiologists, Insitute of Haematology and Transfusion Medicine. All rights reserved. 


\footnotetext{
${ }^{20}$ Department of Hematology and Bone Marrow Transplantation, Medical School of Silesia, Silesian Medical University, Katowice, Poland

${ }^{21}$ Department of Oncological Hematology and Transplantology, Podkarpacie Oncological Center, Brzozów, Poland ${ }^{22}$ Department of Lymphoid Malignancies, Maria Skłodowska-Curie National Research Institute of Oncology, Warsaw, Poland ${ }^{23}$ Department of Hematology and Bone Marrow Transplantation, Nicolaus Copernicus Town Hospital, Toruń, Poland

${ }^{24}$ Department of Hematology, Transplantology and Internal Diseases, Warsaw Medical University, Warsaw, Poland
}

\#SS and AP share first co-authorship; \#" LG is the senior author; all other authors are listed in reverse alphabetical order

\section{Abstract}

Infections are still one of the most common causes of death after hematopoietic cell transplantation (HCT). Antimicrobial prophylaxis plays a crucial role in decreasing non-relapse mortality after HCT.

The objective of this guideline paper was the presentation of current recommendations of antimicrobial prophylaxis for children and adults after hematopoietic cell transplantation, prepared in cooperation with Polish scientific hematological societies. Recommendations were prepared by the working group and finally approved by all 23 Polish transplant centers for children and adults. Existing (European Conference on Infections in Leukemia (ECIL) and European Society of Blood and Marrow Transplantation (EBMT) guidelines, as well as the results of a survey performed among all Polish transplant centers, were the background material for the working group. Recommendations are presented in sections dedicated to antibacterial prophylaxis, antifungal prophylaxis, antiviral prophylaxis, as well as prophylaxis of toxoplasmosis and infections with Pneumocystis jiroveci. Recommendations on the principles of vaccination against COVID-19 are provided based on the state of knowledge in September 2021. A section on guidelines of environmental prophylaxis is also presented.

Key words: hematopoietic cell transplantation, children, adults, incidence, outcome, bacterial infections, viral infections, invasive fungal disease

Acta Haematologica Polonica 2021; 52, 6: 528-542

\section{Introduction}

Despite progress in the diagnostic field and the pharmacotherapy of infections, they are still one of the most common causes of death after hematopoietic cell transplantation (HCT). According to the latest analysis published by the European Society for Blood and Marrow Transplantation (EBMT), infections were responsible for about $22 \%$ of deaths, being the second commonest cause of death after autologous HCT (auto-HCT), and the third commonest cause after allogeneic HCT (allo-HCT) [1].

The post-HCT prophylaxis is adjusted to the risk of specific infections, which in turn depend mainly on the time elapsed after HCT. Traditionally, four phases with different frequencies of infectious categories are distinguished: the very early or pre-engraftment phase (up to 30 days post-HCT); the early post-engraftment phase (between days 30-100); the late post-engraftment phase ( $>100$ days and up to one year); and the very late post-transplant phase ( $>1$ year post-HCT). In the allo-HCT setting, prophylaxis also covers the risk of immunosuppression and graft-versus-host disease (GvHD).
Most infectious complications are reported in the very early and early periods post-HCT. However, in some patients, delayed immune reconstitution leads to a long-lasting vulnerability to certain infections. That is why appropriate antimicrobial prophylaxis remains one of the most critical aspects of post-transplantation care. In Europe, the major trends in this area are designed by the European Conference on Infections in Leukemia (ECIL), in nine editions 2005-2021 covering bacterial, fungal, viral and parasitic infections [2-16].

The objective of this guideline paper was to present current recommendations of antimicrobial prophylaxis in children and adults after hematopoietic cell transplantation, prepared in cooperation with Polish scientific hematological societies.

\section{Material and methods}

Experts in the field of infectious complications after HCT were invited to prepare recommendations on antimicrobial prophylaxis, both for children and adults, after HCT. 
Table I. Grading system of recommendations

\begin{tabular}{l|l}
\hline Strength of recommendation (SoR) & Definition \\
\hline Grade A & Strong support of recommendation for use \\
\hline Grade B & Moderate support of recommendation for use \\
\hline Grade C & Marginal support of recommendation for use \\
\hline Grade D & Support for recommendation against use \\
\hline Quality of evidence (QOE) & Definition \\
\hline Level I & $\begin{array}{l}\text { Evidence from at least one properly designed randomized, controlled trial (orientated on pri- } \\
\text { mary endpoint of trial) }\end{array}$ \\
\hline Level II & Evidence from at least one well-designed clinical trial (including secondary endpoints), wit- \\
& $\begin{array}{l}\text { hout randomization; from cohort or case-controlled analytic studies (preferably from >1 cen- } \\
\text { ter; from multiple time series; or from dramatic results of uncontrolled experiments }\end{array}$ \\
\hline Level III & Evidence from opinions of respected authorities, based on clinical experience, descriptive \\
& case studies, or reports of expert committees
\end{tabular}

Recommendations were analyzed and approved by representatives of all transplant centers which had previously participated in a survey on practices of antimicrobial prophylaxis in Polish transplant centers $[17,18]$.

The presented guidelines are based on ECIL recommendations, adapted to Polish conditions, and supplemented by the results of the survey.

Recommendations are graded based on the modified system of recent ECIL meetings, taking into account the strength of the recommendation and the quality of evidence (Table I) [2, 3].

\section{Prophylaxis of bacterial infections}

\section{Prophylaxis of bacterial infections in adults}

The risk of infections in the pre-engraftment period should be individually assessed for each transplant patient, evaluating patient-, disease-, and treatment-related factors [19]. The level and duration of neutropenia, as well as mucosal damage, are the crucial risk factors of bacterial infections in the pre-engraftment phase. In the late post-transplant period, patients are at risk of infections caused by encapsulated bacteria (e.g. Streptococcus pneumoniae and Haemophilus influenzae) due to hypogammaglobulinemia and functional hyposplenism, resulting from GvHD and its treatment $[20,21]$.

\section{Prophylaxis of bacterial infections in pre-engraftment period}

Fluoroquinolone prophylaxis is recommended in transplant patients who are at high risk of bacterial infections due to expected profound and protracted neutropenia (defined as $<100$ neutrophils/mL for $\geq 7$ days) (Table II) [19, 22, 23]. This refers mainly to allo-HCT with myeloablative conditioning (MAC). In patients treated with allo-HCT with non-myeloablative (NMA) protocols, or with auto-HCT, the risk of prolonged and profound neutropenia and, consequently, the risk of bacterial infections, is lower. In these settings, the possible benefits of prevention should be weighed against its potential harm related to the negative influence of fluoroquinolones on the intestinal microbiome, increased risk of Clostridium difficile infection, and colonization/infection with fluoroquinolone-resistant or multidrug-resistant strains $[22,24]$. Emerging data reporting an increasing frequency of fluoroquinolone-resistant gram-negative bacilli strongly indicates that the antibiotic policy of the transplant center should be adjusted in light of the local epidemiological data [24]. The implementation of an antimicrobial stewardship program is highly recommended in every center to promote optimal management of antibiotics [20, 22, 24].

\section{Prophylaxis of bacterial infections in late} post-transplant period (>100 days post-HCT) Oral prophylaxis with penicillin is recommended during the immunosuppressive treatment for GvHD or hypogammaglobulinemia in areas with low pneumococcal resistance $[20,25]$. Interchangeably, other agents, according to local antibiotic resistance patterns, might be used [20, 25]. An appropriate macrolide may be substituted depending on local practice [20, 25]. An applicable post-transplant vaccination schedule with Pneumococcal and Haemophilus influenzae vaccines plays a crucial role and should be performed in all HCT recipients [20, 25]. Supplementation with intravenous immunoglobulins (IVIG) is useful in patients with severe hypogammaglobulinemia (serum IgG level $<4$ g/L) with accompanying infections [20].

\section{Prophylaxis of bacterial infections in children} Bacterial infections remain a significant challenge in HCT recipients, being an important cause of morbidity in these patients [26]. The incidence of these infections depends on various factors including underlying disease, the phase of treatment, MAC chemotherapy, immunosuppression induced by conditioning, and immunosuppressive effect of the prevention and/or treatment of GvHD [27]. Increasing 
Table II. Recommendations for antibacterial prophylaxis in adults

\begin{tabular}{|c|c|c|}
\hline Population & Recommendation & SoR/QoE \\
\hline \multicolumn{3}{|c|}{ Pre-engraftment period (up to day 30 and beyond) } \\
\hline Allo-HCT (MAC) & Fluoroquinolone prophylaxis & All \\
\hline Allo-HCT (NMA) & Fluoroquinolone prophylaxis & BIII \\
\hline Auto-HCT & Fluoroquinolone prophylaxis & $\mathrm{Cll}$ \\
\hline \multicolumn{3}{|c|}{ Late post-transplant period ( $>100$ days post-HCT) } \\
\hline \multirow{6}{*}{$\begin{array}{l}\text { Allo-HCT (MAC, } \\
\text { NMA) }\end{array}$} & Penicillin prophylaxis & BIII \\
\hline & Macrolide prophylaxis & CIII \\
\hline & $\begin{array}{l}\text { Intravenous immunoglobulins } \\
\text { (IVIG) }\end{array}$ & CIII \\
\hline & Vaccination: & \\
\hline & - pneumococcal vaccine & $\mathrm{Bl}$ \\
\hline & $\begin{array}{l}\text { - Haemophilus influenzae } \\
\text { vaccine }\end{array}$ & BII \\
\hline \multirow[t]{4}{*}{ Auto-HCT } & $\begin{array}{l}\text { Penicillin prophylaxis if TBI } \\
\text { used in conditioning }\end{array}$ & CIII \\
\hline & Vaccination: & \\
\hline & - pneumococcal vaccine & $\mathrm{Bl}$ \\
\hline & $\begin{array}{l}\text { - Haemophilus influenzae } \\
\text { vaccine }\end{array}$ & BII \\
\hline
\end{tabular}

allo-HCT - allogeneic hematopoietic cell transplantation; MAC - myeloablative conditioning; NMA - non-myeloablative conditioning; auto-HCT - autologous hematopoietic cell transplantation; $\mathrm{TBI}$ - total body irradiation

antimicrobial resistance negatively affects prognosis and can influence eligibility for HCT. The high rate of bacterial infection in the peri-transplant period and the emergence of resistance to key antibiotic groups have led to widespread broad-spectrum antibiotic use [3]. Systemic antibacterial prophylaxis is one approach that can reduce the risk of bacterial infections, but carries the risk of drug toxicity or the emergence of antibiotic resistance.

We suggest that systemic antibacterial prophylaxis should not be used routinely for pediatric patients undergoing allo- or auto-HCT during pre-engraftment neutropenia or for those receiving systemic immunosuppression for the treatment of GvHD (DIII) (Table III). The evidence base that underlies this recommendation shows that antibacterial prophylaxis does not reduce mortality of $\mathrm{HCT}$ recipients, while it may have a certain impact on resistance in bacteriemia isolates [28]. Besides the risk of increasing microbial resistance, antibiotics usually given in antibacterial prophylaxis are associated with negative consequences, i.e. musculoskeletal problems or central nervous system-related adverse events after fluoroquinolones and allergic reactions or gastrointestinal disorders after penicillin V [29]. Furthermore, as HCT recipients are routinely managed in a hospital during the high-risk period, there is an opportunity for very early empiric antibiotic administration and supportive care to reduce complications of bacteremia and severe sepsis [30].
Table III. Recommendations for antibacterial prophylaxis in children

\begin{tabular}{l|c|}
\hline Prophylaxis of bacterial infection in children & SoR/QoE \\
\hline Recommendation: Routine antibacterial & DIII \\
prophylaxis for pediatric patients undergoing \\
HCT during pre-engraftment neutropenia is not \\
recommended
\end{tabular}
$\begin{aligned} & \text { As the recommendation is not supported by a randomized, controlled trial, a careful risk-benefit } \\
& \text { evaluation might favor antibacterial prophylaxis in particular patients. }\end{aligned}$

It is important to emphasize that although routine antibacterial prophylaxis for HCT pediatric patients is not recommended, the implementation must always consider individual patient- and treatment-specific risk factors in deciding who merits antibacterial prophylaxis.

\section{Prophylaxis of fungal infections}

Prophylaxis of fungal infections in adults In 2018, the European Conference on Infections in Leukemia (ECIL), the EBMT, the European Organization for Research and Treatment of Cancer, the Immunocompromised Host Society, and the European LeukemiaNet (ELN) published joint recommendations for antifungal prophylaxis [16].

These recommendations were adopted by national centers [31]. The choice of appropriate agent should be phase-specific, and adjusted to the risk of invasive fungal disease (IFD) and the local epidemiology of fungal infections, including construction works. For patients undergoing auto-HCT, routine prophylaxis is not recommended, although fluconazole $400 \mathrm{mg} /$ day as prevention of Candida mucositis during the very early neutropenic phase may be considered (BIII) [32]. For allo-HCT, identified risk factors for mold IFD in the pre-engraftment/engraftment phases include active leukemia, cord blood transplantation (CBT), prior IFD, an alternative donor (AD) HCT recipient with iron overload or early/recurrent cytomegalovirus (CMV) infection or acute GvHD or delayed engraftment ( $\geq 3$-week neutropenia) or high-dose steroids for more than one week ( $\geq 2 \mathrm{mg} / \mathrm{kg}$ ) [33]. The risk factors for the post-engraftment phase include acute GvHD grade III-IV, grade II after AD-HCT, acute GvHD non-responsive to steroids, acute GvHD receiving steroids, and age $>40$ years, subsequent acute and chronic GvHD, secondary neutropenia or recurrent CMV infection after AD-HCT [33, 34].

Antifungal prophylaxis in adults undergoing HCT: neutropenic phase (pre-engraftment)

In centers with mold IFD incidence $<5 \%$, fluconazole is recommended (AI) when combined with mold-directed screening with biomarkers (galactomannan, GM) and/or high resolution computed tomography (HRCT), while an alternative approach should be used in centers with higher incidence (AllI). According to the latest update, mold-active 
Table IV. Recommendations for primary antifungal prophylaxis in adults

\begin{tabular}{|l|c|c|c|}
\hline Anti-fungal agent & \multicolumn{2}{|c|}{ Pre-engraftment } & Post-engraftment \\
\cline { 2 - 4 } & Low risk of mold IFD & High risk of mold IFD & High-risk GvHD \\
\hline Fluconazole p.o./i.v. & $\mathrm{Al}$ & $\mathrm{DIII}$ & $\mathrm{DIII}$ \\
\hline Posaconazole (TDM) p.o. & $\mathrm{BII}$ & $\mathrm{BII}$ & $\mathrm{Al}$ \\
Voriconazole (TDM) p.o./i.v. & $\mathrm{BI}$ & $\mathrm{BI}$ & $\mathrm{BI}$ \\
\hline Micafungin* i.v. & $\mathrm{BI}$ & $\mathrm{Cl}$ & $\mathrm{Cll}$ \\
\hline Liposomal amphotericin B i.v. & $\mathrm{CII}$ & $\mathrm{Cll}$ & $\mathrm{Cll}$ \\
\hline Aerosolized liposomal amphotericin B (plus fluconazole) & $\mathrm{CIII}$ & $\mathrm{BII}$ & No data \\
\hline
\end{tabular}

*No data for other echinocandins: anidulafungin and caspofungin; p.o. - per os; i.v. - intravenous; TDM - therapeutic drug monitoring (recommended)

azoles voriconazole $2 \times 200 \mathrm{mg}(\mathrm{BI})$ or posaconazole $3 \times 200 \mathrm{mg}$ (oral solution) or $1 \times 300 \mathrm{mg}$ (tablets) after a one-day loading dose of $2 \times 300 \mathrm{mg}$ (BII) should be used. Alternative options include micafungin $50 \mathrm{mg}$ intravenous (i.v.) in low-risk (BI) and high-risk centers $(\mathrm{Cl})$ and liposomal amphotericin B IV (CII) [35]. Aerosolized liposomal amphotericin $B$ in a dose of $10 \mathrm{mg}$ twice weekly added to fluconazole $400 \mathrm{mg}$ remains the option for high-risk centers (BII) [16].

Antifungal prophylaxis in adults undergoing HCT: post-engraftment phase

The experts contraindicate fluconazole in patients with GvHD and high-risk factors (AllI), while oral posaconazole continues to be the drug of choice (AI) [16, 36]. A low level of recommendations (CII) for micafungin and liposomal amphotericin $B$ is based on limited data from randomized trials $[16,35]$. The summarized recommendations are presented in Table IV.

The use of azoles poses the risk of drug-to-drug interactions in the HCT recipients, and Polish transplant centers avoid their use during the conditioning [17]. Centers should apply therapeutic drug monitoring (TDM) in the case of voriconazole (plasma target 1-6 mg/L) and posaconazole (plasma target $>0.7 \mathrm{mg} / \mathrm{L}$ ) [16]. Itraconazole, available in Poland in the form of capsules, has no recommendations for antifungal prophylaxis. Preliminary data supports isavuconazole's utility, but more trials are needed to determine its primary prevention role due to reported breakthrough IFD [37, 38].

\section{Prophylaxis of fungal infections in children}

Primary antifungal prophylaxis in children is strongly recommended irrespective of primary diagnosis during the neutropenic phase and until immune reconstitution, and in children with GvHD according to updated guidelines by ECIL-8 [2], and Polish recommendations, including dosing of antifungals [31]. Monitoring of Aspergillus using serum galactomannan (GM) levels is feasible, yet the negative predictive value is relatively high and other molds remain undetected. According to ECIL-8 guidelines, GM monitoring is valuable in children not receiving mold-active prophylaxis, but experts discourage its use in those receiving mold-active prophylaxis due to false-negative results [2].

\section{Antifungal prophylaxis in children undergoing allo-HCT: neutropenic phase (pre-engraftment)}

Primary antifungal prophylaxis is recommended in children undergoing allo-HCT in the neutropenic phase until engraftment (BII). Therapeutic options include fluconazole (effective only against selected yeasts), micafungin, posaconazole, or voriconazole. Due to possible drug-drug interactions, voriconazole should not be used during high-dose chemotherapy.

\section{Antifungal prophylaxis in children undergoing allo-HCT: post-engraftment phase}

In the absence of GvHD, antifungal prophylaxis should be continued after engraftment until immune recovery. In the presence of GvHD treated with augmented immunosuppressive therapy, prophylaxis against mold and yeast infections is recommended (All). The available options include posaconazole $(\mathrm{BI})$ and voriconazole (BI). Posaconazole oral suspension remains the treatment of choice $(\mathrm{BI})$. Its twice-daily body-weight-based dosing algorithm has been proposed by Welzen et al. (Table V) [39]. Alternatively, for pediatric patients, from 1 month to 12 years of age, a starting dose of posaconazole $6 \mathrm{mg} / \mathrm{kg}$ three times daily may be used [40]. Parallel administration of proton pump inhibitors should be avoided during posaconazole prophylaxis. Posaconazole i.v. may be used alternatively for children with acute GVHD weighing $>40 \mathrm{~kg}$ (300 mg daily i.v.). Posaconazole TDM will hopefully be shortly developed in Poland and offered to all transplant centers. A pilot study has been started in cooperation between Wrocław center and MonitLab in Poznań.

\section{Antifungal prophylaxis in children} undergoing auto-HCT

Fluconazole as primary prophylaxis against Candida albicans should be considered. Micafungin or caspofungin may be administered in patients with C. glabrata/C. krusei colonization. 
Table V. Posaconazole dosing algorithm in children

\begin{tabular}{|l|c|c|}
\hline \multirow{2}{*}{ Body weight [kg] } & \multicolumn{2}{|c|}{ Dosing in } \\
\cline { 2 - 3 } & {$[\mathrm{mg}]$} & {$[\mathrm{mL}]$} \\
\hline $10-14$ & $2 \times 120$ & $2 \times 3$ \\
$15-19$ & $2 \times 160$ & $2 \times 4$ \\
$20-24$ & $2 \times 200$ & $2 \times 5$ \\
$25-29$ & $2 \times 220$ & $2 \times 5.5$ \\
$30-34$ & $2 \times 260$ & $2 \times 6.5$ \\
$35-39$ & $2 \times 280$ & $2 \times 7$ \\
$>40$ & $2 \times 300$ & $2 \times 7.5$ \\
\hline
\end{tabular}

Antifungal prophylaxis in children with low risk for IFD development

Antifungal prophylaxis is recommended in selected patients with additional risk factors.

\section{Secondary antifungal prophylaxis}

Secondary antifungal chemoprophylaxis is recommended, targeted against the previous fungal pathogen, for as long as the patient is neutropenic or under immunosuppression (All). Either posaconazole or voriconazole may be considered (Table VI). Off-label isavuconazole may be used in very high-risk patients with previous fungal infections treated successfully with this agent.

\section{Prophylaxis of viral infections}

\section{Prevention of CMV infection and disease}

CMV infection has been associated with increased non-relapse mortality (NRM) in allo-HCT recipients [41]. Antiviral prophylaxis aims to prevent $\mathrm{CMV}$ replication in seropositive patients.

Universal prophylaxis leads to toxicities, detrimental for patients, including clinically significant myelosuppression associated with prolonged use of gancyclovir or valgancyclovir, which may also increase NRM. Moreover, high doses of acyclovir or valacyclovir reduced the risk of CMV infection, but not CMV disease, in randomized studies [42, 43].

Letermovir, a CMV-terminase inhibitor, significantly reduced CMV infection or reactivation and all-cause mortality at 24 weeks in CMV seropositive allo-HCT recipients, with no significant side effects [44]. Letermovir is active only against CMV, and therefore, acyclovir or valacyclovir is necessary to cover herpes simplex virus (HSV)/varicella zoster virus (VZV) prophylaxis. Patients who receive prophylaxis with letermovir should have CMV viremia monitored after drug discontinuation.

Currently, letermovir is the drug of choice for a universal CMV prophylaxis in CMV-seropositive allo-HCT recipients (Table VII). CMV infection and disease risk remains a concern among high-risk patients, including haploidentical HCT
Table VI. Recommendations for antifungal prophylaxis in children undergoing hematopoietic cell transplantation (HCT)

\begin{tabular}{|l|c|c|c|c|}
\hline Drug & $\begin{array}{c}\text { Allo-HCT, } \\
\text { neutropenic } \\
\text { phase }\end{array}$ & $\begin{array}{c}\text { Allo- } \\
\text {-HCT, } \\
\text { GvHD }\end{array}$ & $\begin{array}{c}\text { Auto- } \\
\text {-HCT }\end{array}$ & $\begin{array}{c}\text { Secondary } \\
\text { prophylaxis }\end{array}$ \\
\hline Posaconazole & + & ++ & & + \\
\hline Micafungin & + & & + & \\
\hline $\begin{array}{l}\text { Fluconazole } \\
\text { Voriconazole }\end{array}$ & + & & + & \\
\hline
\end{tabular}

allo-HCT - allogeneic hematopoietic cell transplantation; GVHD - graft-versus-host disease

Table VII. Recommendations for cytomegalovirus infection prophylaxis in allogeneic hematopoietic cell transplantation (allo-HCT) recipients [4]

\begin{tabular}{|l|c|c|}
\hline Therapeutic agent & $\begin{array}{c}\text { Adult } \\
\text { patients }\end{array}$ & $\begin{array}{c}\text { Pediatric } \\
\text { patients }\end{array}$ \\
\hline $\begin{array}{l}\text { Letermovir } 480 \mathrm{mg} / \text { day }(240 \mathrm{mg} / \\
\text { /day, if cyclosporin is co-administe- } \\
\text { red), starts on day of transplantation } \\
\text { or up to } 28 \text { days afterwards, for } 100 \\
\text { days after HCT }\end{array}$ & $\mathrm{Al}$ & - \\
$\begin{array}{l}\text { Valacyclovir } \\
\text { Gancyclovir (2 } 5 \text { mg/kg/day) }\end{array}$ & $\mathrm{BI}$ & \\
$\begin{array}{l}\text { Valgancyclovir } \\
\text { Acyclovir }\end{array}$ & $\mathrm{Cl}$ & $\mathrm{BI}$ \\
\hline $\begin{array}{l}\text { Foscarnet (180 mg/kg/day } \\
\text { in 2-3 doses) }\end{array}$ & $\mathrm{Cll}$ & $\mathrm{Cll}$ \\
Intravenous immunoglobulin & $\mathrm{Cl}$ & $\mathrm{Cl}$ \\
& $\mathrm{DIl}$ & $\mathrm{Cl}$ \\
\hline
\end{tabular}

(haplo-HCT), CBT, and T-cell-depleted (TCD) graft recipients. In this context, letermovir may be preferentially considered in this patient population.

\section{Prevention of primary CMV infection}

CMV-seronegative recipients should receive blood products from seronegative donors or leucocyte-depleted blood products, and the quality standard of less than $1 \times 10^{6} \mathrm{re}-$ sidual leukocytes per unit should be warranted (Al) $[45,46]$. A CMV-seronegative donor should be chosen, when possible, for a CMV-seronegative recipient (Al), for haplo-HCT (AllI) [4]. In a MAC unrelated allo-HCT setting, for the CMV-seropositive recipient, a CMV-seropositive recipient should be chosen (BII). In haplo-HCT with post-transplant cyclophosphamide, a CMV-seropositive or seronegative donor is suitable (BII) [4].

\section{Prevention of CMV infection and disease in children}

In high risk pediatric patients including haplo-HCT, CBT and TCD graft recipients, several agents are recommended for CMV prophylaxis: valacyclovir (BI) $[43,47]$, gancyclovir (Cl) 
Table VIII. Recommendations for prevention of Epstein-Bárr virus (EBV)-post-transplant lymphoproliferative disorder (PTLD) and other EBV-related diseases [6]

\begin{tabular}{l|c|}
\hline Recommendation & Grading \\
\hline Allo-HCT recipients and donors should be tested for EBV antibodies & All \\
\hline $\begin{array}{l}\text { For EBV-seronegative recipients, an EBV-seronegative donor should be chosen } \\
\text { For EBV-seropositive recipients, an EBV-seropositive donor might be preferred because of presence of EBV-CTL }\end{array}$ & BII \\
\hline $\begin{array}{l}\text { Allo-HCT recipients at high risk for EBV-PTLD should be closely monitored for signs and symptoms related to PTLD } \\
\text { After high-risk allo-HCT, prospective EBV-DNA-emia monitoring should be introduced }\end{array}$ & CIII \\
$\begin{array}{l}\text { For HLA-fully matched related, non-T-cell depleted graft recipients without GVHD, routine EBV-DNA-emia screening is not } \\
\text { recommended }\end{array}$ & All \\
\hline $\begin{array}{l}\text { For auto-HCT patients, routine monitoring for EBV-DNA-emia before and after HCT is not recommended } \\
\text { allo-HCT - allogeneic hematopoietic cell transplantation; CTL-cytotoxic Tlymphocyte; HLA-human leukocyte antigen; GVHD - graft-versus-host disease }\end{array}$ & DIII
\end{tabular}

[48, 49], acyclovir (Cl) [42], foscarnet (Cl) [50] and valgancyclovir (CII). Data on letermovir use in children [51, 52] is insufficient to provide any recommendations for its use in a pediatric population. Due to a minor effect on prevention of CMV infection and disease, CMV-specific immunoglobulins and polyvalent IVIG are currently not recommended (DI) [53].

\section{Prophylaxis of EBV-post-transplant lymphoproliferative disorder (PTLD) in adults and children}

Active prevention is based on optimization of donor choice, conditioning regimen, and GvHD prevention (Table VIII). Data on Epstein-Bárr virus (EBV) prophylaxis in transplant settings is limited. Passive prophylaxis approaches, including a low dose of rituximab, unselected donor lymphocyte infusion (DLI), or EBV-specific cytotoxic T lymphocyte (EBV-CTL) infusion, can decrease the incidence of EBV-DNAemia. It should be noted, however, that the use of DLI for EBV-DNAemia or EBV-post-transplant lymphoproliferative disorder (PTLD) is not reported nowadays by transplant centers. Rituximab-based preemptive therapy can prevent the development of EBV-PTLD, benefiting recipients with higher loads of EBV-DNA. To date, there is no consensus as to when to initiate prophylactic or preemptive treatment. Current preemptive strategies for EBV-PTLD include reduction (RI) or withdrawal of immunosuppression therapy when feasible (All) [54], rituximab (All) [55, 56], and EBV-CTL (CIII) $[57,58]$. Antiviral drugs are currently not recommended (DIII) [59] in the prophylaxis of EBV-reactivation (Table IX). $\mathrm{RI}$ is defined as a sustained decrease of at least $20 \%$ of the daily dose of immunosuppressive drugs [6].

\section{Prophylaxis of HSV disease}

Prophylaxis with an antiviral drug in herpes simplex virus (HSV)-seronegative allo-HCT recipients is not recommended (DIII) because primary HSV infections in this population are unusual. Due to the high rate of HSV reactivation in HSV-seropositive patients, prophylactic oral or IV acyclovir has been administered routinely in allo-HCT recipients,
Table IX. Preemptive treatment strategy for Epstein-Bárr virus (EBV)-post-transplant lymphoproliferative disorder (PTLD)

\begin{tabular}{|c|c|}
\hline Therapeutic agent/strategy & Grading \\
\hline Rituximab (B-cell depletion) & All \\
\hline $\begin{array}{l}\text { Reduction or withdrawal of immunosuppressive } \\
\text { therapy (RI) }\end{array}$ & All \\
\hline Adoptive transfer of EBV-CTL & $\mathrm{Cll}$ \\
\hline DLI & CIII \\
\hline Antiviral agents & DII \\
\hline IVIg, interferon & DIII \\
\hline
\end{tabular}

Table X. Recommendations for herpes simplex virus (HSV) disease prophylaxis in HSV-seropositive adult patients $[13,60]$

\begin{tabular}{l|c}
\hline Therapeutic agent & Grading \\
\hline Acyclovir from $3 \times 200 \mathrm{mg}$ to $2 \times 800 \mathrm{mg} /$ day p.o. & Al \\
Acyclovir $2 \times 250 \mathrm{mg} / \mathrm{m}^{2}$ or $2 \times 5 \mathrm{mg} / \mathrm{kg}$ i.v. & Al \\
Valacyclovir $2 \times 500 \mathrm{mg} /$ day p.o. & All \\
Famcyclovir $2 \times 500 \mathrm{mg} /$ day & BIII \\
\hline
\end{tabular}

p.o. - per os; i.v. - intravenous

lasting 3-5 weeks after HCT (Table X). Allo-HCT recipients who develop GVHD or receive immunosuppressive treatment require prolonged HSV prophylaxis (BII). Intravenous acyclovir should be considered for patients with poor drug absorption or due to severe mucositis (CIII). Valacyclovir is an alternative prophylactic agent with good bioavailability, and famcyclovir may be considered as an alternative treatment $[13,60]$. Famcyclovir is not yet available in Poland.

There are no specific recommendations for HSV prevention in a pediatric setting. In addition, there is no data on famcyclovir's safety and efficacy in children younger than 12 years. That is why a recommendation for this drug in a pediatric population cannot be given. However, according to the medical product characteristics, acyclovir dosing in children $>2$ years old is the same as for adults, while a half dose is recommended for children $<2$ years old. 
Table XI. Recommendations for voricella zoster virus (VZV) disease prophylaxis for allogeneic hematopoietic cell transplantation (allo-HCT) recipients $[13,60]$

Acyclovir $2 \times 800 \mathrm{mg} / \mathrm{d}$ p.o. (for children: $2 \times 20 \mathrm{mg} / \mathrm{kg}$ ) or valacyclovir once or twice daily:

- for one year after allo-HCT or

- in the presence of GvHD and immunosuppressive therapy beyond one year

Prophylaxis after VZV exposure in VZV-seronegative patients

Passive immunization with specific VZIG i.v. or i.m. $(0.2-1 \mathrm{~mL} / \mathrm{kg})$ or normal IVIG $(300-500 \mathrm{mg} / \mathrm{kg})$ should be given immediately after exposure $(<96 \mathrm{~h})$, for patients who have chronic GvHD, or who are on immunosuppressive treatment, or who have undergone HCT within the last two years

Acyclovir $4 \times 800 \mathrm{mg} /$ daily $\left(4 \times 600 \mathrm{mg} / \mathrm{m}^{2}\right.$ for children) or valacyclovir $3 \times 1,000 \mathrm{mg} /$ daily, $(3 \times 500 \mathrm{mg}$ if body weight $<40 \mathrm{~kg}$ ), or famcyclovir $3 \times 500 \mathrm{mg} /$ daily; therapy should be administered from days 3-21 after exposure

If a second exposure occurs $>21$ days after a passive immunization or after the prophylaxis administration, a prophylaxis should be reintroduced

Seronegative HCT recipients should receive prophylaxis in case of exposure to a VZV vaccine having a varicella-like rash

\section{Prophylaxis of VZV disease}

The determination of VZV serostatus before transplantation should be done in all allo-HCT recipients (Alll). Acyclovir and valacyclovir prophylaxis were proven effective in several trials, and they are a primary preventive approach in the allo-HCT setting (Tables XI, XII) Prophylaxis in auto-HCT recipients is controversial [13]. Recommendations for adults and children are the same.

VZV-seronegative HCT recipients should not have contact with people with chickenpox or zoster (All) and vaccine recipients experiencing a rash after varicella vaccine (BIII). Vaccination of VZV-seronegative individuals who may be in contact with the patients during transplantation is a worthwhile preventive strategy, but should be performed at least four weeks before the start of conditioning (BIII). Zoster immune globulin (ZIG) and varicella-zoster immune globulin (VZIG) are passive antibody prophylaxis in seronegative recipients after exposure to varicella. If passive immunization is not available, acyclovir, valacyclovir, or famcyclovir as post-exposure prophylaxis are recommended.

\section{Prophylaxis for BK Polyomavirus-associated hemorrhagic cystitis (BKV-HC)}

No randomized controlled trial has yet been published to give a specific recommendation for the prevention of BKV-HC in adults and children. Anti-BKV prophylaxis is not available. Hyperhydration plus forced diuresis during conditioning regimen (BII) and/or bladder irrigation through a triple lumen Foley catheter are of limited value in a prophylactic setting (CII) $[7,61]$. The risk of fluid overload for hyperhydration and the invasiveness of catheter positioning must be taken into consideration.

Fluoroquinolones (ciprofloxacin) are not effective for prophylaxis, and in fact increase the risk of antibiotic
Table XII. Administration of acyclovir in children

\begin{tabular}{l|l}
\hline Indication & Dose \\
\hline Prophylaxis HSV & $2 \times 5 \mathrm{mg} / \mathrm{kg}$ p.o. \\
Treatment of HSV mucositis & $3 \times 5 \mathrm{mg} / \mathrm{kg}$ i.v.; 10 days \\
Treatment of HSV visceral & $3 \times 10 \mathrm{mg} / \mathrm{kg} ; 14-21$ days \\
Prophylaxis VZV in IgG- & $2 \times 20 \mathrm{mg} / \mathrm{kg}$ \\
-seropositives & (max. $2 \times 800 \mathrm{mg})$ \\
Post-exposure prophylaxis & $2 \times 20 \mathrm{mg} / \mathrm{kg}$ \\
VZV in lgG-seronegatives & to $4 \times 600 \mathrm{mg} / \mathrm{m}^{2} ; 21$ days
\end{tabular}

p.o. - per os; HSV - herpes simplex virus; VZV - voricella zoster virus; IgG - immunoglobulin G

resistance (DII). Two studies showed a reduction of BKV replication in ciprofloxacin recipients, but without any impact on BKV-HC incidence [62, 63].

\section{Prevention for HHV-6B infection (encephalitis)}

Patients after CBT are at significant risk for both HHV-6 reactivation and HHV-6 encephalitis [64]. Routine testing of blood for HHV-6B in allo-HCT and testing donors or recipients for inherited chromosomally integrated HHV6 (CI-HHV-6) is not recommended due to a lack of recognized preemptive treatment thresholds, and the uncertain efficacy of preemptive therapy (DII). HHV-6 PCR results must be interpreted with caution due to the possibility of Cl-HHV-6 in the recipient or allografted cells. In patients with $\mathrm{Cl}-\mathrm{HHV}-6$, latent HHV-6 DNA will be detected by PCR test in all clinical samples. However, this may not reveal viral replication, and antivirals will not reduce the viral load (in whole blood samples, HHV-6 viral loads are typically $>10^{6}$ copies $/ \mathrm{mL}$ ). Encephalitis is the only well recognized HHV-6 disease in allo-HCT recipients; other clinical manifestations are less 
Table XIII. Recommendations for adenovirus disease prophylaxis for allogeneic hematopoietic cell transplantation recipients [14]

\begin{tabular}{|c|c|}
\hline Recommendation & Grading \\
\hline $\begin{array}{l}\text { Prophylaxis with an antiviral drug is not recom- } \\
\text { mended }\end{array}$ & BIII \\
\hline $\begin{array}{l}\text { In patients with viremia and at least one risk } \\
\text { factor, preemptive therapy with cidofovir } \\
\text { ( } 3-5 \mathrm{mg} / \mathrm{kg} / \text { week for } 2-3 \text { weeks, followed by } \\
3-5 \mathrm{mg} / \mathrm{kg} \text { every other week or } 1 \mathrm{mg} / \mathrm{kg} \text {, three } \\
\text { times a week) }\end{array}$ & BII \\
\hline
\end{tabular}

established. There is insufficient evidence to recommend the routine use of antiviral prophylaxis or preemptive therapy for HHV-6 infection in adults and children (DII) [5].

\section{Prophylaxis of adenovirus (ADV) infection}

ADV infection is diagnosed mainly in the 2-3 months after allo-HCT. Although some patients are asymptomatic and eliminate the virus spontaneously, a quick increase of viral load to multi-organ disease with organ insufficiency is possible. Nevertheless, prophylaxis with any antiviral drug is not recommended for adults and children (BIII) (Table XIII). Cidofovir is recommended for preemptive antiviral treatment in allo-HCT patients with viremia and at least one risk factor both for children (allo-HCT with in vivo or ex vivo T-cell depletion; allo-HCT with unrelated donor graft; allo-HCT with unrelated cord blood graft; grade III-IV graft-versus-host disease; and severe lymphopenia with $<200$ cells/ $\mu \mathrm{L}$ PB) and for adults (allo-HCT with haploidentical donor or unrelated cord blood graft; grade III-IV GvHD; severe lymphopenia with $<200$ cells/ $\mu \mathrm{L}$ PB; and treatment with alemtuzumab) (BII) [14].

\section{Prevention of community-acquired respiratory virus infection (CARV) in adults and children}

Good personal hygiene (i.e. frequent hand washing, covering mouth when coughing and sneezing, safe disposal of nasal and oral secretions) is strongly recommended for allo-HCT patients and their contact persons (All) (Table XIV). Patients undergoing HCT should avoid people with respiratory tract infections in the hospital and the community (All). Young children should not be allowed to visit patients and wards because of the greater risk of CARV transmission with prolonged shedding (BII). Entering HCT wards and seeing HCT patients should be restricted for healthcare workers and visitors with respiratory tract infections (All). In HCT patients with respiratory tract infection inside care facilities, infection control measures should be incorporated, including isolation rooms and protective equipment (coat, gloves, masks, eye protection) for staff and visitors (All). Outpatients with respiratory tract infections should be placed in rooms separated from other HCT patients
Table XIV. Recommendations on prevention of community-acquired respiratory virus (CARV) for allogeneic hematopoietic cell transplantation (allo-HCT) recipients [12]

\begin{tabular}{|c|c|}
\hline Recommendation & Grading \\
\hline $\begin{array}{l}\text { Good personal hygiene (frequent hand washing, } \\
\text { covering mouth when coughing and sneezing, safe } \\
\text { disposal of nasal and oral secretions) is strongly } \\
\text { recommended for allo-HCT patients and contact } \\
\text { persons }\end{array}$ & All \\
\hline $\begin{array}{l}\text { HCT patients should avoid contact with people with } \\
\text { respiratory tract infections in the hospital and the } \\
\text { community }\end{array}$ & All \\
\hline $\begin{array}{l}\text { Young children should not be allowed to visit } \\
\text { patients and wards because of the greater risk } \\
\text { of CARV exposure, prolonged shedding, and } \\
\text { transmission }\end{array}$ & BII \\
\hline $\begin{array}{l}\text { Healthcare workers and visitors with respiratory } \\
\text { tract infections should be prevented from visiting } \\
\text { HCT patients and wards }\end{array}$ & All \\
\hline $\begin{array}{l}\text { In HCT patients with respiratory tract infection } \\
\text { inside care facilities, infection control measures } \\
\text { should be used, including isolation rooms and } \\
\text { protective equipment to support staff and visitors } \\
\text { (coat, gloves, masks, eye protection) }\end{array}$ & All \\
\hline $\begin{array}{l}\text { Outpatients with respiratory tract infections should } \\
\text { be admitted and treated in rooms separated from } \\
\text { other HCT patients and the HCT ward }\end{array}$ & All \\
\hline $\begin{array}{l}\text { In pediatric HCT recipients aged <2 years, } \\
\text { palivizumab may be considered during RSV } \\
\text { outbreaks in the community, indicating an } \\
\text { increased exposure }\end{array}$ & CIII \\
\hline $\begin{array}{l}\text { In HCT recipients with hypogammaglobulinemia } \\
(<4 \mathrm{~g} / \mathrm{L}) \text {, IVIg may reduce the risk of morbidity and } \\
\text { mortality secondary to respiratory tract infections } \\
\text { caused by CARV }\end{array}$ & CIII \\
\hline
\end{tabular}

and an HCT ward (All). In pediatric HCT recipients aged $<2$ years, palivizumab, an intravenous monoclonal antibody specific for respiratory syncytial virus (RSV), may be considered during RSV outbreaks in the community (CIII). In HCT recipients with hypogammaglobulinemia ( $<4 \mathrm{~g} / \mathrm{L})$, IVlg may reduce the risk of morbidity and mortality secondary to respiratory tract infections caused by CARV (CIII) [12].

\section{Prophylaxis of influenza in adults and children}

To avoid transmission of influenza, patients and healthcare staff should apply the same general precautions for preventing CARV infection.

Vaccination with seasonal inactivated influenza vaccine is recommended yearly in all HCT recipients older than 6 months (All) (Table XV). The vaccine is given at least three months after $\mathrm{HCT}$, and preferably prior to the flu season (BIII). Due to the risk of suboptimal immunity in case 
Table XV. Recommendations on prevention of influenza for hematopoietic cell transplantation (HCT) recipients [15]

\begin{tabular}{l|c}
\hline Prevention of influenza with vaccination & Grading \\
\hline $\begin{array}{l}\text { Vaccination with seasonal inactivated influenza } \\
\text { vaccine is recommended in all HCT recipients older } \\
\text { than } 6 \text { months }\end{array}$ & All \\
$\begin{array}{l}\text { The vaccine should be given at least three months } \\
\text { after HCT, preferably prior to the influenza season }\end{array}$ & BIII \\
\hline $\begin{array}{l}\text { Post-exposure antiviral prophylaxis } \\
\text { Oseltamivir for at least } 10 \text { days }\end{array}$ & CIII \\
\hline
\end{tabular}

of vaccination performed $<6$ months post-HCT, a second dose of vaccine can be considered [60]. After exposure to a confirmed or probable case of flu, antiviral prophylaxis with oseltamivir for at least 10 days is recommended in HCT recipients who are less than 12 months after HCT, or later if immunocompromised (CIII) [15].

\section{Prophylaxis of SARS-CoV-2/COVID-19 in adults and children}

A new coronavirus - severe acute respiratory syndrome coronavirus 2 (SARS-CoV-2) - appeared at the end of 2019, and caused a disease called COVID-19. The WHO classified COVID-19 as a pandemic on 11 March 2020 [65]. Mortality among HCT patients caused by this disease was over $22 \%$ in adults and $7 \%$ in children [66].

There is no specific antiviral agent active against SARS-CoV-2. Thus, non-specific preventive measures typical for CARV infections are mandatory. A number of new-generation vaccines are available nowadays. We recommend following EBMT guidelines: HCT patients should be vaccinated with whatever vaccine is available but not live-attenuated vaccine or vaccine containing replicating viral vectors [67]. Vaccination against COVID-19 should take priority over the regular vaccinations program; the vaccine should routinely be administered alone. The vaccination program should be initiated at least three months after HCT; although if the transmission rate is low, it is advised to wait six months after HCT to initiate vaccination. Controlled GvHD is not a contraindication for vaccination [67]. It will be necessary to administer additional or periodic shots. As of September 2021, children over 12 years should be vaccinated. As of December 2021, children over 5 years should be vaccinated (note added at proof).

\section{Prophylaxis for toxoplasmosis}

Toxoplasmosis is a life-threatening condition with an incidence depending on seroprevalence in the population. Toxoplasmosis is seen mainly after allo-HCT, but cases after auto-HCT have been published. The disease occurs mainly as reactivation in previously infected individuals, however primary infection or re-infection after transplant can be also observed. The main risk factors for its development include patient seropositivity, allo-HCT and GVHD.

Recommendations on prevention of toxoplasmosis [68]:

1. In all patients and their donors, serostatus should be determined prior to transplant.

2. Avoiding eating uncooked meat of any type or drinking contaminated water should be recommended to all patients before and after transplant.

3. Primary chemoprophylaxis should be offered to seronegative recipients transplanted from a seropositive donor.

4. Secondary chemoprophylaxis is recommended to all seropositive recipients, regardless of donor serostatus.

5. Chemoprophylaxis is based on TMP/SMX taken at least three times per week for $\geq 6$ months:

a) $80 / 400 \mathrm{mg}$ daily,

b) $160 / 800 \mathrm{mg}$, three days per week.

6. Alternative chemoprophylaxis includes:
a) Pyrimethamine and sulfadoxine (fancidar): $2-3$ tab- lets per week,
b) Atovaquone: $1,500 \mathrm{mg}$ daily,
c) Dapsone: $100 \mathrm{mg}$ daily.

7. Weekly gPCR monitoring is advocated when prophylaxis is not being used, is used for less than six months, or when the dose or type of prophylactic medicines are not adequate (i.e. pentamidine).

\section{Prophylaxis for Pneumocystis jiroveci}

Pneumocystis jiroveci (PjP, previously known as PcP) causes life-threatening pneumonia in immunocompromised patients. According to ECIL guidance, primary prophylaxis should be offered to all recipients after allo-HCT.

The drug of choice is TMP/SMX (trimethoprim/sulfamethoxazole) in a dose of $80 / 400 \mathrm{mg}$ daily or $160 / 800 \mathrm{mg}$, three times weekly from engraftment for at least six months or longer where immunosuppression is ongoing. Second-line alternatives include: pentamidine aerosolized (300 mg per month) or IV, or atovaquone (1,500 mg per day), or dapsone $(2 \times 50 \mathrm{mg}$, daily) [8].

\section{Environmental prophylaxis}

Global recommendations on protective environment in the HCT setting have been prepared internationally (Table XVI) [69] but adopted locally [18, 70]. Additionally, general precautions for patients and healthcare staff to prevent CARV infection should always be implemented in everyday clinical practice.

\section{Discussion}

Antimicrobial prophylaxis plays a crucial role in lessening NRM after HCT [71]. These joint recommendations summarize the most important aspects based on available data to 
Table XVI. Global Recommendations on Protective Environment

Global Recommendations on Protective Environ-
ment (GRPE)

1. Ventilation: $\geq 12$ air changes per hour

2. Central or point-of-use HEPA filters with 99.97\% efficiency for removing particles $\leq 0.3 \mu \mathrm{m}$ in diameter

3. Filters should be replaced regularly based on manufacturers' recommendations, and, when there is ongoing construction, filtration efficiency should be monitored frequently to best determine appropriate time for replacement

4. Directed airflow so that air intake occurs at one side of room and air exhaust occurs at opposite side

5. Consistent positive air pressure differential between patient's room and hallway $\geq 2.5 \mathrm{~Pa}$

6. Well-sealed rooms (e.g. filling gaps between walls and windows, outlets, floor, and ceiling) should always be used for HCT patients to prevent infiltration of air from outside room that could allow entry of spores and hinder maintenance of proper pressure differential

7. Continuous pressure monitoring, especially while rooms are occupied

8. Self-closing doors to maintain constant pressure differentials

9. Monitoring systems that will set off an alarm when pressure differential between any protective environment room and adjacent hallway or anteroom falls $<2.5 \mathrm{~Pa}$, to alert staff to possible engineering failures

10. To enable nursing staff to observe HCT recipient even when doors are closed, windows can be installed in either door or wall of HCT recipient's room

help transplant physicians in their everyday practice. We have tried to adjust these recommendations to a local market. However, we also included new antimicrobial agents like letermovir and isavuconazole.

Although limited refunding options severely hinder access to them in Poland, we believe that this situation will change in the near future. The market of azoles differs from that of other European countries. That is why itraconazole in oral suspension was not mentioned, while we listed posaconazole in tablets, as this form may soon become available in Poland. Although, according to the current ECIL or EBMT guidelines, isavuconazole is nowadays not listed in recommendations for prophylactic treatment, we provided this possibility both for children and adults. This is due to the increasing number of new publications regarding its off-label use in antifungal prophylaxis in a population of patients with hematological malignancies and patients undergoing allogeneic transplantation. There are several advantages of this drug compared to other antifungal azoles: less drug interactions, less hepatic toxicity, and less renal impairment.

Antibacterial prophylaxis remains an unsolved issue due to the side effects of fluoroquinolones, unfavorable influence on gut microbiota, and increased bacterial resistance to this group of antibiotics. Transplant centers follow different strategies: continue this type of prophylaxis, or abandon pharmacological prevention with increased attention to neutropenic fever, or replace fluoroquinolones with another agent. Randomized prospective studies should be designed to determine which attitude is the optimal solution for HCT patients.

Moreover, there is an urgent need to implement and standardize TDM of voriconazole and posaconazole in our laboratories. This would increase the safety and efficacy of antifungal management.

Regarding CARV, we have given general recommendations with no stress on the current SARS-CoV-2 pandemic since most preventive precautions are common while the therapeutic approach is very dynamic and systematically updated by the EBMT.

Due to constant development in the field of HCT and new evidence regarding antimicrobial prophylaxis and treatment being published constantly, regular updates of these recommendations will be required.

\section{Authors' contributions}

Design of study: JS, LG. Analysis of recommendations and final approval: all authors. The following authors wrote primary versions of respective sections: AP (Introduction, Antifungal prophylaxis in adults, Discussion); KK (Antifungal prophylaxis in children); AF (Antibacterial prophylaxis in adults); OZS (Antibacterial prophylaxis in children); BPJ (Antiviral prophylaxis in adults); KC (Antiviral prophylaxis in children); LG (Prophylaxis of toxoplasmosis and infections with PjP); JS (Introduction, Methods, COVID-19 prophylaxis, Environmental prophylaxis, Discussion).

\section{Conflicts of interest}

JS - lecture fees or participant in meetings supported by Pfizer, MSD, Gilead, TEVA, and Astellas. KC - lecture fees or participant in meetings supported by MSD and Gilead. KK - lecture fees or participant in meetings supported by Pfizer, MSD, and Gilead. BB - lecture fees or participant in meetings supported by Amgen, and Celgene/BMS. All other authors declared no conflict of interest.

\section{Financial support}

None.

\section{Ethics}

The work described in this article has been carried out in accordance with The Code of Ethics of the World Medical 
Association (Declaration of Helsinki) for experiments involving humans; EU Directive 2010/63/EU for animal experiments; Uniform Requirements for manuscripts submitted to Biomedical journals.

\section{References}

1. Styczyński J, Tridello G, Koster L, et al. Infectious Diseases Working Party EBMT. Death after hematopoietic stem cell transplantation: changes over calendar year time, infections and associated factors. Bone Marrow Transplant. 2020; 55(1): 126-136, doi: 10.1038/ s41409-019-0624-z, indexed in Pubmed: 31455899.

2. Groll A, Pana D, Lanternier F, et al. 8th European Conference on Infections in Leukaemia: 2020 guidelines for the diagnosis, prevention, and treatment of invasive fungal diseases in paediatric patients with cancer or post-haematopoietic cell transplantation. Lancet Oncol. 2021; 22(6): e254-e269, doi: 10.1016/s1470-2045(20)30723-3, indexed in Pubmed: 33811813.

3. Lehrnbecher T, Averbuch D, Castagnola E, et al. 8th European Conference on Infections in Leukaemia: 2020 guidelines for the use of antibiotics in paediatric patients with cancer or post-haematopoietic cell transplantation. The Lancet Oncol. 2021; 22(6): e270-e280, doi: 10.1016/s1470-2045(20)30725-7, indexed in Pubmed: 33811814.

4. Ljungman P, de la Camara R, Robin C, et al. 2017 European Conference on Infections in Leukaemia group. Guidelines for the management of cytomegalovirus infection in patients with haematological malignancies and after stem cell transplantation from the $2017 \mathrm{Eu}-$ ropean Conference on Infections in Leukaemia (ECIL 7). Lancet Infect Dis. 2019; 19(8): e260-e272, doi: 10.1016/S1473-3099(19)301070 , indexed in Pubmed: 31153807.

5. Ward KN, Hill JA, Hubacek P, et al. 2017 European Conference on Infections in Leukaemia (ECIL). Guidelines from the 2017 European Conference on Infections in Leukaemia for management of HHV-6 infection in patients with hematologic malignancies and after hematopoietic stem cell transplantation. Haematologica. 2019; 104(11): 2155-2163, doi: 10.3324/haematol.2019.223073, indexed in Pubmed: 31467131.

6. Styczynski J, van der Velden W, Fox CP, et al. Sixth European Conference on Infections in Leukemia, a joint venture of the Infectious Diseases Working Party of the European Society of Blood and Marrow Transplantation (EBMT-IDWP), the Infectious Diseases Group of the European Organization for Research and Treatment of Cancer (EORTC-IDG), the International Immunocompromised Host Society (ICHS) and the European Leukemia Net (ELN). Management of Epstein-Barr Virus infections and post-transplant lymphoproliferative disorders in patients after allogeneic hematopoietic stem cell transplantation: Sixth European Conference on Infections in Leukemia (ECIL-6) guidelines. Haematologica. 2016; 101(7): 803-811, doi: 10.3324/haematol.2016.144428, indexed in Pubmed: 27365460.

7. Cesaro S, Dalianis T, Hanssen Rinaldo C, et al. ECIL-6 Group. ECIL guidelines for the prevention, diagnosis and treatment of BK polyomavirus-associated haemorrhagic cystitis in haematopoietic stem cell transplant recipients. J Antimicrob Chemother. 2018; 73(1): 12-21, doi: 10.1093/jac/dkx324, indexed in Pubmed: 29190347.

8. Maertens J, Cesaro S, Maschmeyer G, et al. 5th European Conference on Infections in Leukaemia (ECIL-5), a joint venture of the European Group for Blood and Marrow Transplantation (EBMT), the European Organisation for Research and Treatment of Cancer (EORTC), the Immunocompromised Host Society (ICHS) and the European LeukemiaNet
(ELN). ECIL guidelines for preventing Pneumocystis jirovecii pneumonia in patients with haematological malignancies and stem cell transplant recipients. J Antimicrob Chemother. 2016; 71(9): 2397-2404, doi: 10.1093/jac/dkw157, indexed in Pubmed: 27550992.

9. Averbuch D, Cordonnier C, Livermore DM, et al. ECIL4, a joint venture of EBMT, EORTC, ICHS, ESGICH/ESCMID and ELN. Targeted therapy against multi-resistant bacteria in leukemic and hematopoietic stem cell transplant recipients: guidelines of the 4th European Conference on Infections in Leukemia (ECIL-4, 2011). Haematologica. 2013; 98(12): 1836-1847, doi: 10.3324/haematol.2013.091330, indexed in Pubmed: 24323984.

10. Averbuch D, Orasch C, Cordonnier C, et al. ECIL4, a joint venture of EBMT, EORTC, ICHS, ESGICH/ESCMID and ELN. European guidelines for empirical antibacterial therapy for febrile neutropenic patients in the era of growing resistance: summary of the 2011 4th European Conference on Infections in Leukemia. Haematologica. 2013; 98(12): 1826-1835, doi: 10.3324/haematol.2013.091025, indexed in Pubmed: 24323983.

11. Tissot F, Agrawal S, Pagano L, et al. ECIL-6 guidelines for the treatment of invasive candidiasis, aspergillosis and mucormycosis in leukemia and hematopoietic stem cell transplant patients. Haematologica. 2017; 102(3): 433-444, doi: 10.3324/haematol.2016.152900, indexed in Pubmed: 28011902.

12. Hirsch HH, Martino R, Ward KN, et al. Fourth European Conference on Infections in Leukaemia (ECIL-4): guidelines for diagnosis and treatment of human respiratory syncytial virus, parainfluenza virus, metapneumovirus, rhinovirus, and coronavirus. Clin Infect Dis. 2013; 56(2): 258-266, doi: 10.1093/cid/cis844, indexed in Pubmed: 23024295.

13. Styczynski J, Reusser P, Einsele H, et al. Second European Conference on Infections in Leukemia. Management of HSV, VZV and EBV infections in patients with hematological malignancies and after SCT: guidelines from the Second European Conference on Infections in Leukemia. Bone Marrow Transplant. 2009; 43(10): 757-770, doi: 10.1038/bmt.2008.386, indexed in Pubmed: 19043458.

14. Matthes-Martin S, Feuchtinger T, Shaw PJ, et al. Fourth European Conference on Infections in Leukemia. European guidelines for diagnosis and treatment of adenovirus infection in leukemia and stem cell transplantation: summary of ECIL-4 (2011). Transpl Infect Dis. 2012; 14(6): 555-563, doi: 10.1111/tid.12022, indexed in Pubmed: 23146063.

15. Engelhard D, Mohty B, de la Camara R, et al. European guidelines for prevention and management of influenza in hematopoietic stem cell transplantation and leukemia patients: summary of ECIL-4 (2011), on behalf of ECIL, a joint venture of EBMT, EORTC, ICHS, and ELN. Transpl Infect Dis. 2013; 15(3): 219-232, doi: 10.1111/tid.12054, indexed in Pubmed: 23363310.

16. Maertens JA, Girmenia C, Brüggemann RJ, et al. European Conference on Infections in Leukaemia (ECIL), a joint venture of the European Group for Blood and Marrow Transplantation (EBMT), the European Organization for Research and Treatment of Cancer (EORTC), the Immunocompromised Host Society (ICHS) and European LeukemiaNet (ELN). European guidelines for primary antifungal prophylaxis in adult haematology patients: summary of the updated recommendations from the European Conference on Infections in Leukaemia. J Antimicrob Chemother. 2018; 73(12): 3221-3230, doi: 10.1093/ jac/dky286, indexed in Pubmed: 30085172.

17. Styczyński J, Czyżewski K, Ussowicz M, et al. Antimicrobial prophylaxis in patients after hematopoietic cell transplantation: results of a survey of the Polish Federation of Bone Marrow Transplant Centers. Acta Haematol Pol. 2020; 51(3): 183-186, doi: 10.2478/ahp-2020-0032. 
18. Styczyński J, Czyżewski K, Ussowicz M, et al. Antimicrobial prophylaxis in patients after hematopoietic cell transplantation: results of a survey of the Polish Federation of Bone Marrow Transplant Centers. Acta Haematol Pol. 2020; 51(3): 183-186, doi: 10.2478/ahp-2020-0032.

19. Taplitz RA, Kennedy EB, Bow EJ, et al. Antimicrobial prophylaxis for adult patients with cancer-related immunosuppression: ASCO and IDSA clinical practice guideline update summary. J Oncol Pract. 2018; 14(11): 692-695, doi: 10.1200/JOP.18.00366, indexed in Pubmed: 30179525.

20. Carreras E, Dufour C, Mohty M, Kröger N. The EBMT Handbook: hematopoietic stem cell transplantation and cellular therapies. Springer, Cham 2019.

21. Czyżewski K, Styczyński J, Giebel S, et al. for Polish Society of Pediatric Oncology and Hematology and Polish Society of Hematology and Blood Transfusion. Age-dependent determinants of infectious complications profile in children and adults after hematopoietic cell transplantation: lesson from the nationwide study. Ann Hematol. 2019; 98(9): 2197-2211, doi: 10.1007/s00277-019-03755-2, indexed in Pubmed: 31321454.

22. Mikulska M, Averbuch D, Tissot F, et al. European Conference on Infections in Leukemia (ECIL). Fluoroquinolone prophylaxis in haematological cancer patients with neutropenia: ECIL critical appraisal of previous guidelines. J Infect. 2018; 76(1): 20-37, doi: 10.1016/j. jinf.2017.10.009, indexed in Pubmed: 29079323.

23. Egan G, Robinson PD, Martinez JPD, et al. Efficacy of antibiotic prophylaxis in patients with cancer and hematopoietic stem cell transplantation recipients: A systematic review of randomized trials. Cancer Med. 2019; 8(10): 4536-4546, doi: 10.1002/cam4.2395, indexed in Pubmed: 31274245.

24. European Centre for Disease Prevention and Control. Surveillance of antimicrobial resistance in Europe - annual report of the European Antimicrobial Resistance Surveillance Network (EARS-Net) 2017. ECDC, Stockholm 2018.

25. Davies JM, Lewis MPN, Wimperis J, et al. British Committee for Standards in Haematology. Review of guidelines for the prevention and treatment of infection in patients with an absent or dysfunctional spleen: prepared on behalf of the British Committee for Standards in Haematology by a working party of the Haemato-Oncology task force. Br J Haematol. 2011; 155(3): 308-317, doi: 10.1111/j.13652141.2011.08843.x, indexed in Pubmed: 21988145.

26. Zając-Spychała 0, Wachowiak J, Frączkiewicz J, et al. Multidrug-resistant bacterial infections in children undergoing haematopoietic stem cell transplantation over a 6-year period: analysis of the Polish Pediatric Group for Hematopoietic Stem Cell Transplantation. J Appl Microbiol. 2020; 128(1): 292-300, doi: 10.1111/jam.14452, indexed in Pubmed: 31529556.

27. Zając-Spychała O, Wachowiak J, Pieczonka A, et al. Bacterial infections in pediatric hematopoietic stem cell transplantation recipients: incidence, epidemiology, and spectrum of pathogens: report of the Polish Pediatric Group for Hematopoietic Stem Cell Transplantation. Transpl Infect Dis. 2016; 18(5): 690-698, doi: 10.1111/tid.12581, indexed in Pubmed: 27479544.

28. Alexander S, Fisher BT, Gaur AH, et al. Children's Oncology Group. Effect of levofloxacin prophylaxis on bacteremia in children with acute leukemia or undergoing hematopoietic stem cell transplantation: a randomized clinical trial. JAMA. 2018; 320(10): 995-1004, doi: 10.1001/jama.2018.12512, indexed in Pubmed: 30208456.

29. Tandan M, Cormican M, Vellinga A. Adverse events of fluoroquinolones vs. other antimicrobials prescribed in primary care: A systematic review and meta-analysis of randomized controlled trials. Int
J Antimicrob Agents. 2018; 52(5): 529-540, doi: 10.1016/j.ijantimicag.2018.04.014, indexed in Pubmed: 29702230.

30. Lehrnbecher T, Fisher BT, Phillips B, et al. Guideline for antibacterial prophylaxis administration in pediatric cancer and hematopoietic stem cell transplantation. Clin Infect Dis. 2020; 71(1): 226-236, doi: 10.1093/cid/ciz1082, indexed in Pubmed: 31676904.

31. Gil L, Kałwak K, Piekarska A, et al. Antifungal management in adults and children with hematological malignancies or undergoing hematopoietic cell transplantation: recommendations of Polish Society of Hematology and Blood Transfusion, Polish Society of Pediatric Oncology and Hematology, and Polish Adult Leukemia Study Group, 2020. Acta Haematologica Polonica. 2020; 51(2): 60-72, doi: 10.2478/ ahp-2020-0014.

32. Jantunen E, Salonen J, Juvonen E, et al. Invasive fungal infections in autologous stem cell transplant recipients: a nation-wide study of 1188 transplanted patients. Eur J Haematol. 2004; 73(3): 174-178, doi: 10.1111/j.1600-0609.2004.00273.x, indexed in Pubmed: 15287914.

33. Girmenia C, Raiola AM, Piciocchi A, et al. Primary prophylaxis of invasive fungal diseases in allogeneic stem cell transplantation: revised recommendations from a consensus process by Gruppo Italiano Trapianto Midollo Osseo (GITMO). Biol Blood Marrow Transplant. 2014; 20(8): 1080-1088, doi: 10.1016/j.bbmt.2014.02.018, indexed in Pubmed: 24582783.

34. Blennow 0, Remberger M, Törlén J, et al. Risk factors for invasive mold infections and implications for choice of prophylaxis after allogeneic stem cell transplantation. Biol Blood Marrow Transplant. 2016; 22(9): 1684-1689, doi: 10.1016/j.bbmt.2016.06.008, indexed in Pubmed: 27311967.

35. van Burik JAH, Ratanatharathorn V, Stepan DE, et al. National Institute of Allergy and Infectious Diseases Mycoses Study Group. Micafungin versus fluconazole for prophylaxis against invasive fungal infections during neutropenia in patients undergoing hematopoietic stem cell transplantation. Clin Infect Dis. 2004; 39(10): 1407-1416, doi: 10.1086/422312, indexed in Pubmed: 15546073.

36. Ullmann AJ, Lipton JH, Vesole DH, et al. Posaconazole or fluconazole for prophylaxis in severe graft-versus-host disease. N Engl J Med. 2007; 356(4): 335-347, doi: 10.1056/NEJMoa061098, indexed in Pubmed: 17251530.

37. Stern A, Su Y, Lee YJ, et al. A single-center, open-label trial of isavuconazole prophylaxis against invasive fungal infection in patients undergoing allogeneic hematopoietic cell transplantation. Biol Blood Marrow Transplant. 2020; 26(6): 1195-1202, doi: 10.1016/j. bbmt.2020.02.009, indexed in Pubmed: 32088367.

38. Fontana L, Perlin DS, Zhao Y, et al. Isavuconazole prophylaxis in patients with hematologic malignancies and hematopoietic cell transplant recipients. Clin Infect Dis. 2020; 70(5): 723-730, doi: 10.1093/ cid/ciz282, indexed in Pubmed: 30958538.

39. Welzen MEB, Brüggemann RJM, Van Den Berg JM, et al. A twice daily posaconazole dosing algorithm for children with chronic granulomatous disease. Pediatr Infect Dis J. 2011; 30(9): 794-797, doi: 10.1097/INF.0b013e3182195808, indexed in Pubmed: 21772229.

40. Arrieta AC, Sung L, Bradley JS, et al. A non-randomized trial to assess the safety, tolerability, and pharmacokinetics of posaconazole oral suspension in immunocompromised children with neutropenia. PLoS One. 2019; 14(3): e0212837, doi: 10.1371/journal.pone.0212837, indexed in Pubmed: 30913226.

41. Styczyński J. ABC of viral infections in hematology: focus on herpesviruses. Acta Haematol Pol. 2019; 50(3): 159-166, doi: 10.2478/ ahp-2019-0026. 
42. Prentice HG, Gluckman E, Powles RL, et al. Impact of long-term acyclovir on cytomegalovirus infection and survival after allogeneic bone marrow transplantation. European Acyclovir for CMV Prophylaxis Study Group. Lancet. 1994; 343(8900): 749-753, doi: 10.1016/s01406736(94)91835-x, indexed in Pubmed: 7907729.

43. Ljungman P, de La Camara R, Milpied N, et al. Valacyclovir International Bone Marrow Transplant Study Group. Randomized study of valacyclovir as prophylaxis against cytomegalovirus reactivation in recipients of allogeneic bone marrow transplants. Blood. 2002; 99(8): 3050-3056, doi: 10.1182/blood.v99.8.3050, indexed in Pubmed: 11929799.

44. Marty FM, Ljungman PT, Chemaly RF, et al. Letermovir prophylaxis for cytomegalovirus in hematopoietic-cell transplantation. N Engl J Med. 2017; 377(25): 2433-2444, doi: 10.1056/NEJMoa1706640, indexed in Pubmed: 29211658.

45. Ljungman P, Larsson K, Kumlien G, et al. Leukocyte depleted, unscreened blood products give a low risk for CMV infection and disease in CMV seronegative allogeneic stem cell transplant recipients with seronegative stem cell donors. Scand J Infect Dis. 2002; 34(5): 347-350, doi: 10.1080/00365540110080412, indexed in Pubmed: 12069017.

46. Nichols WG, Price TH, Gooley T, et al. Transfusion-transmitted cytomegalovirus infection after receipt of leukoreduced blood products. Blood. 2003; 101(10): 4195-4200, doi: 10.1182/blood-2002-10-3143, indexed in Pubmed: 12531791.

47. Winston DJ, Yeager AM, Chandrasekar PH, et al. Valacyclovir Cytomegalovirus Study Group. Randomized comparison of oral valacyclovir and intravenous ganciclovir for prevention of cytomegalovirus disease after allogeneic bone marrow transplantation. Clin Infect Dis. 2003; 36(6): 749-758, doi: 10.1086/367836, indexed in Pubmed: 12627359.

48. Winston DJ, Ho WG, Bartoni K, et al. Ganciclovir prophylaxis of cytomegalovirus infection and disease in allogeneic bone marrow transplant recipients. Results of a placebo-controlled, double-blind trial. Ann Intern Med. 1993; 118(3): 179-184, doi: 10.7326/0003-4819-118-3-199302010-00004, indexed in Pubmed: 8380243.

49. Goodrich JM, Bowden RA, Fisher L, et al. Ganciclovir prophylaxis to prevent cytomegalovirus disease after allogeneic marrow transplant. Ann Intern Med. 1993; 118(3): 173-178, doi: 10.7326/0003-4819118-3-199302010-00003, indexed in Pubmed: 8380242.

50. Reusser P, Einsele H, Lee J, et al. Infectious Diseases Working Party of the European Group for Blood and Marrow Transplantation. Randomized multicenter trial of foscarnet versus ganciclovir for preemptive therapy of cytomegalovirus infection after allogeneic stem cell transplantation. Blood. 2002; 99(4): 1159-1164, doi: 10.1182/blood. v99.4.1159, indexed in Pubmed: 11830461.

51. Styczyński J, Tridello G, Xhaard A, et al. Use of letermovir in off-label indications: Infectious Diseases Working Party of European Society of Blood and Marrow Transplantation retrospective study. Bone Marrow Transplant. 2021; 56(5): 1171-1179, doi: 10.1038/s41409-02001166-w, indexed in Pubmed: 33288863.

52. Styczyński J, Czyżewski K, Dębski R. Primary prophylaxis with letermovir for prevention of CMV infection in two children. Acta Haematol Pol. 2020; 51(4): 263-264, doi: 10.2478/ahp-2020-0046.

53. Raanani P, Gafter-Gvili A, Paul M, et al. Immunoglobulin prophylaxis in hematopoietic stem cell transplantation: systematic review and meta-analysis. J Clin Oncol. 2009; 27(5): 770-781, doi: 10.1200/ JC0.2008.16.8450, indexed in Pubmed: 19114702.
54. Cesaro S, Pegoraro A, Tridello G, et al. A prospective study on modulation of immunosuppression for Epstein-Barr virus reactivation in pediatric patients who underwent unrelated hematopoietic stem-cell transplantation. Transplantation. 2010; 89(12): 1533-1540, doi: 10.1097/TP.0b013e3181dd6c0a, indexed in Pubmed: 20463647.

55. Muramatsu H, Takahashi Y, Shimoyama Y, et al. CD20-negative Epstein-Barr virus-associated post-transplant lymphoproliferative disease refractory to rituximab in a patient with severe aplastic anemia. Int J Hematol. 2011; 93(6): 779-781, doi: 10.1007/s12185-0110870-3, indexed in Pubmed: 21559814.

56. Worth A, Conyers R, Cohen J, et al. Pre-emptive rituximab based on viraemia and $T$ cell reconstitution: a highly effective strategy for the prevention of Epstein-Barr virus-associated lymphoproliferative disease following stem cell transplantation. Br J Haematol. 2011; 155(3): 377-385, doi: 10.1111/j.1365-2141.2011.08855.x, indexed in Pubmed: 21910716.

57. Barker JN, Doubrovina E, Sauter C, et al. Successful treatment of EBV-associated posttransplantation lymphoma after cord blood transplantation using third-party EBV-specific cytotoxic T lymphocytes. Blood. 2010; 116(23): 5045-5049, doi: 10.1182/ blood-2010-04-281873, indexed in Pubmed: 20826724.

58. Doubrovina E, Oflaz-Sozmen B, Prockop SE, et al. Adoptive immunotherapy with unselected or EBV-specific T cells for biopsy-proven EBV+ lymphomas after allogeneic hematopoietic cell transplantation. Blood. 2012; 119(11): 2644-2656, doi: 10.1182/blood-2011-08-371971, indexed in Pubmed: 22138512.

59. Czyzewski K, Dziedzic M, Salamonowicz M, et al. Epidemiology, outcome and risk factors analysis of viral infections in children and adolescents undergoing hematopoietic cell transplantation: antiviral drugs do not prevent Epstein-Barr virus reactivation. Infect Drug Resist. 2019; 12: 3893-3902, doi: 10.2147/IDR.S224291, indexed in Pubmed: 31908501.

60. Ljungman P, Styczynski J, Einsele H. Viral infections. In: Carreras E, Dufour C, Mohty M, Kroger N. ed. The EBMT handbook: hematopoietic stem cell transplantation and cellular therapies. Spiringer, Cham 2019: 281-290.

61. Hadjibabaie M, Alimoghaddam K, Shamshiri AR, et al. Continuous bladder irrigation prevents hemorrhagic cystitis after allogeneic hematopoietic cell transplantation. Urol Oncol. 2008; 26(1): 43-46, doi: 10.1016/j.urolonc.2006.12.015, indexed in Pubmed: 18190829.

62. Leung AYH, Chan MTL, Yuen KY, et al. Ciprofloxacin decreased polyoma BK virus load in patients who underwent allogeneic hematopoietic stem cell transplantation. Clin Infect Dis. 2005; 40(4): 528-537, doi: 10.1086/427291, indexed in Pubmed: 15712075.

63. Miller AN, Glode A, Hogan KR, et al. Efficacy and safety of ciprofloxacin for prophylaxis of polyomavirus BK virus-associated hemorrhagic cystitis in allogeneic hematopoietic stem cell transplantation recipients. Biol Blood Marrow Transplant. 2011; 17(8): 1176-1181, doi: 10.1016/j.bbmt.2010.12.700, indexed in Pubmed: 21185389.

64. Ogata M, Satou T, Kadota Ji, et al. Human herpesvirus 6 (HHV-6) reactivation and HHV-6 encephalitis after allogeneic hematopoietic cell transplantation: a multicenter, prospective study. Clin Infect Dis. 2013; 57(5): 671-681, doi: 10.1093/cid/cit358, indexed in Pubmed: 23723198.

65. Ljungman P, Mikulska M, de la Camara R, et al. European Society for Blood and Marrow Transplantation, European Society for Blood and Marrow Transplantation. The challenge of COVID-19 and hematopoietic cell transplantation; EBMT recommendations for management 
of hematopoietic cell transplant recipients, their donors, and patients undergoing CAR T-cell therapy. Bone Marrow Transplant. 2020; 55(11): 2071-2076, doi: 10.1038/s41409-020-0919-0, indexed in Pubmed: 32404975.

66. Ljungman P, de la Camara R, Mikulska M, et al. COVID-19 and stem cell transplantation; results from an EBMT and GETH multicenter prospective survey. Leukemia. 2021; 35(10): 2885-2894, doi: 10.1038/ s41375-021-01302-5, indexed in Pubmed: 34079042.

67. Ljungman P, Cesaro S, Cordonnier C, Mikulska M, Styczynski J, de la Camara R. COVID-19 vaccines. EBMT recommendations. https://www. ebmt.org/ (September 5, 2021).

68. Martino R. Other life-threatening infections. In: Carreras E, Dufour C, Mohty M, Kroger N. ed. The EBMT handbook: hematopoietic stem cell transplantation and cellular therapies. Springer, Cham 2019: 291-299.

69. Tomblyn M, Chiller T, Einsele H, et al. Center for International Blood and Marrow Research, National Marrow Donor program, European Blood and MarrowTransplant Group, American Society of Blood and Marrow Transplantation, Canadian Blood and Marrow Transplant Group, Infectious Diseases Society of America,
Society for Healthcare Epidemiology of America, Association of Medical Microbiology and Infectious Disease Canada, Centers for Disease Control and Prevention. Guidelines for preventing infectious complications among hematopoietic cell transplantation recipients: a global perspective. Biol Blood Marrow Transplant. 2009; 15(10): 1143-1238, doi: 10.1016/j.bbmt.2009.06.019, indexed in Pubmed: 19747629.

70. Styczynski J, Tridello G, Donnelly JP, et al. Protective environment for hematopoietic cell transplant (HSCT) recipients: The Infectious Diseases Working Party EBMT analysis of global recommendations on health-care facilities. Bone Marrow Transplant. 2018; 53(9): 1131-1138, doi: 10.1038/s41409-018-0141-5, indexed in Pubmed: 29535381.

71. Ifversen M, Meisel R, Sedlacek P, et al. Supportive care during pediatric hematopoietic stem cell transplantation: prevention of infections. A Report From Workshops on Supportive Care of the Paediatric Diseases Working Party (PDWP) of the European Society for Blood and Marrow Transplantation (EBMT). Front Pediatr. 2021; 9: 705179, doi: 10.3389/fped.2021.705179, indexed in Pubmed: 34395344. 